\title{
Analisis Sensor Pengukuran Konsentrasi Glukosa Prinsip Macrobending Pada Serat Optik Multimode Step-Index
}

\author{
Nura Hajar Hafida dan Agus Rubiyanto \\ Departemen Fisika, Fakultas Ilmu Alam, Institut Teknologi Sepuluh Nopember (ITS) \\ e-mail: arubi@physics.its.ac.id
}

\begin{abstract}
Abstrak-Telah dikembangkan sensor konsentrasi glukosa dengan prinsip macrobending dari serat optik multimode stepindex dengan variasi panjang kupasan $2 \mathrm{~cm}, 3 \mathrm{~cm}$, dan $4 \mathrm{~cm}$. Setiap panjang kupasan dilengkungkan dengan diameter kelengkungan $2 \mathrm{~cm}, 3 \mathrm{~cm}$, dan $4 \mathrm{~cm}$. Larutan glukosa yang diuji memiliki konsentrasi $0 \%$ (aquades), 5\%, 10\%, $15 \%$ dan $25 \%$. Sumber cahaya yang digunakan LED dengan panjang gelombang $660 \mathrm{~nm}$ dan detektor yang digunakan yaitu BF5R-D1N yang telah dikalibrasi dengan menggunakan Optical Power Meter. Dari hasil pengukuran diperoleh bahwa semakin besar diameter kelengkungan serat optik semakin besar pula daya keluaran, dan semakin panjang daerah kupasan semakin kecil daya keluaran.
\end{abstract}

Kata Kunci-Konsentrasi glukosa, Macrobending, Serat Optik.

\section{PENDAHULUAN}

G LUKOSA merupakan kelompok senyawa karbohidrat sederhana atau monosakarida. Glukosa berfungsi sebagai sumber energi untuk sel-sel otak, sel saraf, dan sel darah merah. Darah manusia mengandung glukosa dalam konsentrasi tetap yaitu 70-100 $\mathrm{mg} / \mathrm{dL}$. Dalam keadaan kekurangan gula darah disebut dengan hipoglikemi yang dapat menyebabkan tubuh tidak mendapat sumber energi, hingga dapat menyebabkan kan kematian. Sedangkan dalam keadaan kelebihan gula darah disebut dengan hiperglikemi, yang dapat menyebabkan penyakit diabetes. Secara global, menurut WHO sekitar 422 juta orang dewasa pada tahun 2014 menderita diabetes dan pada tahun 2015 sebanyak 1.6 juta penderita diabetes meninggal. Selain itu diabetes dapat meningkatkan resiko penyakit jantung, kebutaan, stroke, serta gagal ginjal. Sehingga dibutuhkan sensor untuk dapat mendeteksi kadar glukosa.

Salah satu cara yang digunakan untuk mendeteksi glukosa yaitu dengan sensor serat optik plastik. Serat optik merupakan devais pandu gelombang cahaya medium dielektrik dan umumnya bekerja sebagai media transmisi gelombang cahaya dengan bentuk silinder. Sensor serat optik polimer mempunyai beberapa kelebihan diantaranya bandwith yang lebar, sederhana, murah, ringan, beroperasi pada cahaya tampak, lebih fleksibel, tidak berinterferensi, sensitivitas tinggi, menggunakan piranti uji sederhana dan murah, dan lebih aman dari serat optik kaca yang memerlukan sumber cahaya laser [1]. Serat optik dapat digunakan sebagai sensor pengukuran konsentrasi larutan, dan pada bidang medis sebagai sensor napas [2], sebagai sensor pengukuran gula darah [3][4].

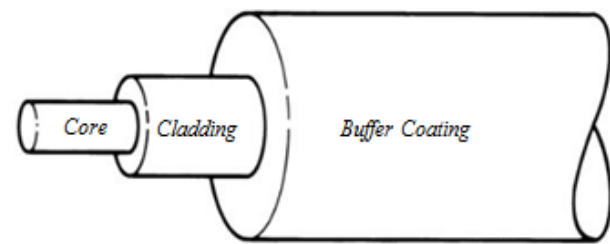

Gambar 1. Struktur penyusun serat optic.

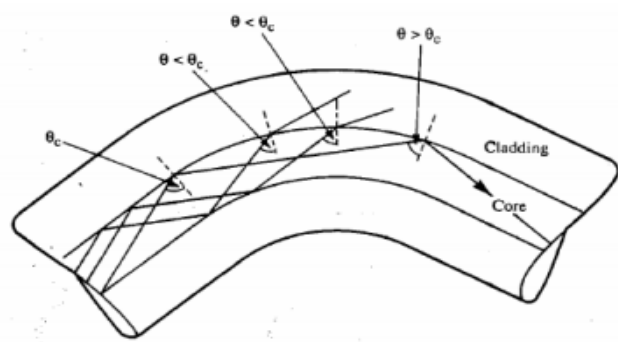

Gambar 2. Penjalaran sinar pada inti serat optik dengan adanya lengkungan.

Serat optik adalah devais pandu gelombang yang menggunakan medium dielektrik dan umumnya bekerja sebagai media transmisi gelombang cahaya dengan bentuk silinder. Secara umum serat optik terdiri dari tiga bagian utama yaitu inti (core), kulit (cladding), dan jaket (coating). Bagian core merupakan saluran utama pada pemanduan gelombang cahaya yang mempunyai indeks bias terbesar $\left(n_{1}\right)$. Inti serat optik adalah sebuah batang silinder terbuat dari bahan dielektrik bahan silica $\left(\mathrm{SiO}_{2}\right)$, biasanya diberi doping dengan germanium oksida $\left(\mathrm{GeO}_{2}\right)$ atau fosfor penta oksida $\left(\mathrm{P}_{2} \mathrm{O}_{5}\right)$ untuk menaikkan indeks biasnya Cladding mempunyai indeks bias $\left(\mathrm{n}_{2}\right)$ yang lebih rendah dibandingkan indeks bias core ${ }^{[5]}$ Cladding berfungsi untuk mengurangi loss dari inti ke udara luar, mengurangi loss hamburan dari permukaan inti dan melindungi serat dari kontaminasi penyerapan permukaan serta menambah kekuatan mekanis . Coating merupakan bagian terluar dari serat optic yang berfungsi sebagai pelindung core dan cladding [5].Struktur penyusun serat optik ditunjukan dengan Gambar 1.

Macrobend (lekukan skala makro) Lekukan tajam pada sebuah kabel serat optik dapat menyebabkan timbulnya rugi daya yang cukup serius, dan lebih jauh lagi kemungkinan terjadinya kerusakan mekanis (pecahnya serat optik). Pada Gambar 2 berkas cahaya memiliki sudut datang yang melebihi sudut kritis, sehingga berkas cahaya dipantulkan seluruhnya kembali kedalam inti. Sehingga sinar di dalam inti terus terpandu hingga ujung serat optik. 


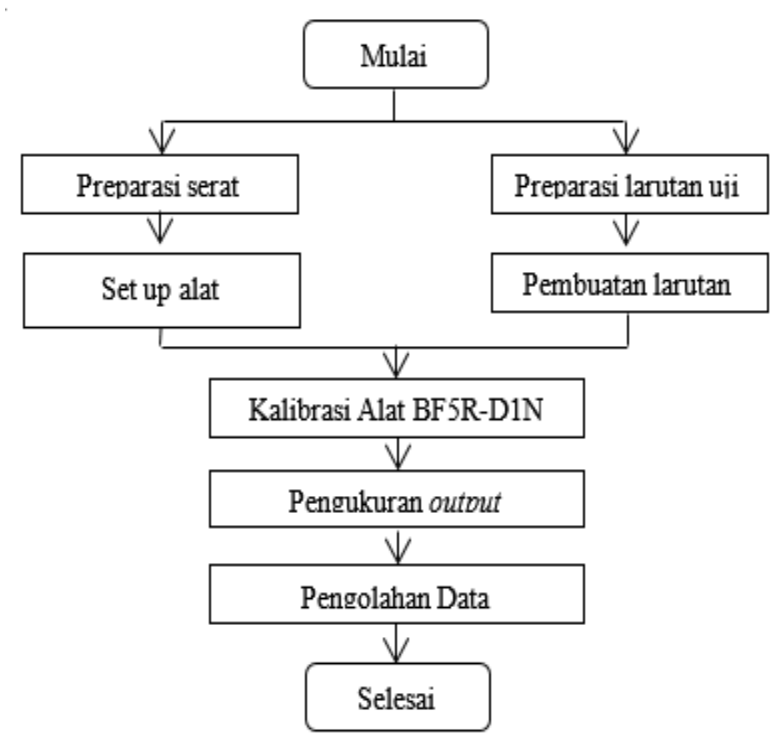

Gambar 3. Diagram Alir Penelitian.

Jika serat optik dilengkungkan, seperti pada Gambar 2 maka garis normal akan berubah arahnya mengikuti permukaan inti akibatnya sudut sinar datang menjadi lebih kecil dibandingkan dengan sudut kritis, sehingga sinar dapat menembus inti. Semakin kecil jari-jari lengkungan maka semakin besar rugi daya yang timbul [6].

Gelombang evanescent adalah gelombang yang mengalami penurunan amplitudo secara eksponensial akibat melalui medium yang lebih renggang. Di dalam serat optik, sebagian gelombang terserap dalam cladding dan daya menurun secara eksponensial. Gelombang evanescent terjadi ketika sinar datang yang masuk tidak seluruhnya terpantulkan akan tetapi ada sebagian yang ditransmisikan ke medium antara prisma dengan lapisan tipis yang dikenal dengan peristiwa Frustrated Total Internal Reflection (FTIR) [7].

Konsentrasi larutan adalah perbandingan zat terlarut terhadap pelarutnya. Massa zat terlarut berpengaruh terhadap massa jenis larutan, dimana sekain besar massa zat, maka massa jenis akan semakin besar pula, dengan syarat volume tetap.

Indeks bias, adalah perbandingan laju cahaya dalam ruang hampa terhadap laju cahaya dalam medium. Konsentrasi larutan dan indeks bias memiliki hubungan linier,artinya semakin besar konsentrasi larutan, indeks bias juga akan semakin besar [8].

Secara mikroskopik, ada beberapa faktor yang menyebabkan beberapa peredaman intensitas cahaya. Yang pertama adalah hamburan dalam serat optik dan juga microbending. Pada molekul-molekulini yang mempengaruhi indeks bias, baik pada cladding maupun pada bagian core [5].

\section{METODOLOGI PENELITIAN}

\section{A. Alat dan Bahan}

Peralatan yang digunakan dalam penelitian ini antara lain, power supply, BF5R D1-N 2 buah, din rail 2 buah, statip, selotip, gunting, cutter, penggaris, pengupas serat optik
Tabel 1.

Nilai yang terbaca pada BF5R-D1-N

\begin{tabular}{cc}
\hline \hline Tegangan $(\mathrm{V})$ & BF5R-D1-N \\
\hline 8 & 1997 \\
8,5 & 2253 \\
9 & 2325 \\
9,5 & 2432 \\
10 & 2465 \\
\hline \hline
\end{tabular}

Tabel 2 .

\begin{tabular}{ll}
\hline \hline Tegangan $(\mathrm{V})$ & OPM $(\mathrm{mW})$ \\
\hline 8 & 0,276 \\
8,5 & 0,310 \\
9 & 0,345 \\
9,5 & 0,372 \\
10 & 0,379 \\
\hline \hline
\end{tabular}

(akrilik), fiber cutter, gelas beker $250 \mathrm{ml}$, magnetic stirer dan hot plate, timbangan, gelas plastik, mikroskop stereo, optical power meter (OPM).

Bahan yang digunakan dalam penelitian ini antara lain, serat optik multimode step index FD-620-10, aseton 96\%, glukosa, dan aquades.

\section{B. Cara Kerja}

Langkah kerja yang dilakukan pada penelitian ini dimulai dengan memotong serat optik dengan menggunakan fiber cutter sepanjang $30 \mathrm{~cm}$ sebanyak 9 buah, Selanjutnya dilakukan pengupasan ditengah bagian serat dengan panjang kupasan $2 \mathrm{~cm}, 3 \mathrm{~cm}$, dan $4 \mathrm{~cm}$ yang masing-masing sebanyak 3 buah, dengan menggunakan pengupas serat optik (akrilik) dan cutter. Selanjutnya dilakukan pengupasan cladding dengan cara merendam bagian serat optik yang telah terkelupas coatingnya kedalam aseton $96 \%$ selama kurang lebih 30 menit. Kemudian serat optik dibentuk single loop dengan variasi diameter $2 \mathrm{~cm}, 3 \mathrm{~cm}$, dan $4 \mathrm{~cm}$.

Tahap berikutnya dilakukan pengamatan struktur permukaan core. Tahap ini bertujuan untuk mengetahui kerataan permukaan core. Pengamatan ini dilakukan dengan menggunakan mikroskop stereo dengan meletakan serat optik yang telah dikupas pada meja preparat dan dilakukan perbesaran mikro sehingga dapat diamati pada komputer yang terhubung ke mikroskop stereo.

Kemudian dibuat larutan glukosa, larutan glukosa yang akan dibuat terdiri dari 6 konsentrasi $0 \%, 5 \%, 10 \%, 15 \%$, $20 \%$, dan 25\%. Pada pembuatan larutan glukosa 5\% dibutuhkan 5 gram glukosa dalam 100ml aquades. Langkah awal melarutkan glukosa dalam aquades yaitu menimbang glukosa dengan menggunakan timbangan, kemudian glukosa yang sudah ditimbang ditambahkan aquades $30 \mathrm{ml}$ yang selajutnya diaduk dengan magnetic stirrer dan diberi suhu $110^{\circ} \mathrm{C}$ selama 15 menit atau sampai glukosa terlarut seluruhnya yang ditandai dengan larutan menjadi bening, setelah glukosa terlarut oleh aquades sebanyak $30 \mathrm{ml}$, ditambahkan lagi aquades $70 \mathrm{ml}$. 


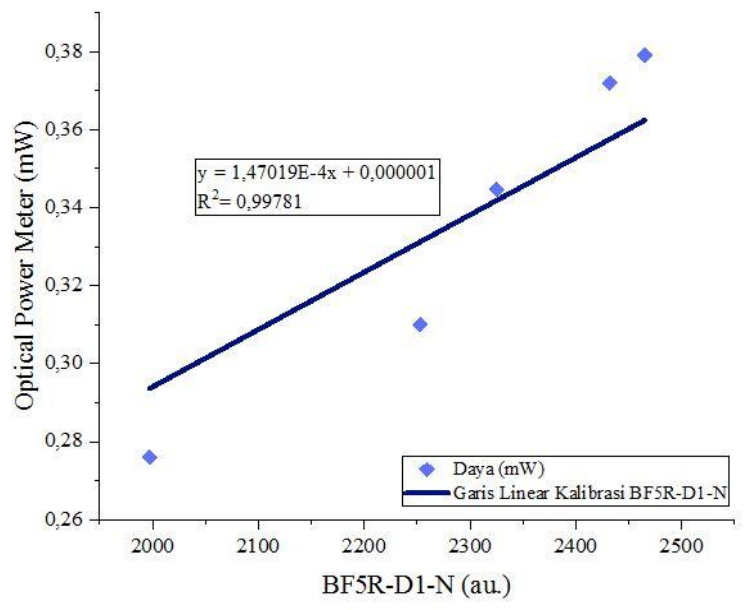

Gambar 4. Kalibrasi BF5R-D1-N dengan Optical Power Meter.

Dilakukan tahap kalibrasi, kalibrasi dilakukan dengan cara menghubungkan input BF5R-D1-N dengan output BF5R-D1$\mathrm{N}$ menggunakan serat optik sepanjang $10 \mathrm{~cm}$, diamati perubahan keluaranya seiring dengan bertambahnya tegangan yang diberikan, dan dilakukan hal yang sama input BF5R-D1$\mathrm{N}$ dihubungkan dengan detektor pada Optical Power Meter dengan serat optik sepanjang $10 \mathrm{~cm}$ dan diamati perubahan daya keluaranya seiring bertambahnya tegangan.

Kemudian dilakukan pengukuran daya keluaran dengan menghubungkan ujung-ujung serat optik yang telah dilengkungkan dan dimasukan dalam wadah, dengan sumber cahaya dan detektor pada BF5R-D1-N, setiap pergantian konsentrasiglukosa dilakukan pencucian wadah.

\section{Diagram Alir Penelitian}

Diagram alir pada penelitian dapat dilihat pada Gambar 3.

\section{ANALISA DATA DAN PEMBAHASAN}

\section{A. Analisa Data}

BF5R-D1-N merupakan sensor serat optik yang terdiri dari sumber cahaya dan detektor. Sumber cahaya pada BF5R-D1$\mathrm{N}$ merupakan LED warna merah dengan panjang gelombang $660 \mathrm{~nm}$. Detektor pada BF5R-D1-N adalah fototransistor tipe NPN.

Kalibrasi ini dilakukan karena nilai yang terbaca pada BF5R-D1-N merupakan nilai tanpa satuan, sehingga dibutuhkan kalibrasi dengan mengan menggunakan Optical Power Meter sehingga didapat nilai daya keluaran dengan satuan Watt. Nilai yang terbaca pada BF5R-D1-N dan Optical Power Meter dapat dilihat pada Tabel 1 dan 2.

Dari data diatas kemudian diolah menjadi grafik pada Gambar 4 dan didapat regresi linearnya. Regresi linear merupakan suatu persamaan yang membentuk hubungan antara variabel terikat y dan variabel bebas $\mathrm{x}$. Pada grafik tersebut nilai regresi linear $\mathrm{y}=1,47019 \mathrm{E}-4 \mathrm{x}+0,000001$, dan koefisien determinasi $\mathrm{R}^{2}=0,99781$ hal ini berarti $99,78 \%$ nilai yang terbaca pada BF5R-D1-N berkorelasi dengan nilai daya yang terbaca pada Optical Power Meter.

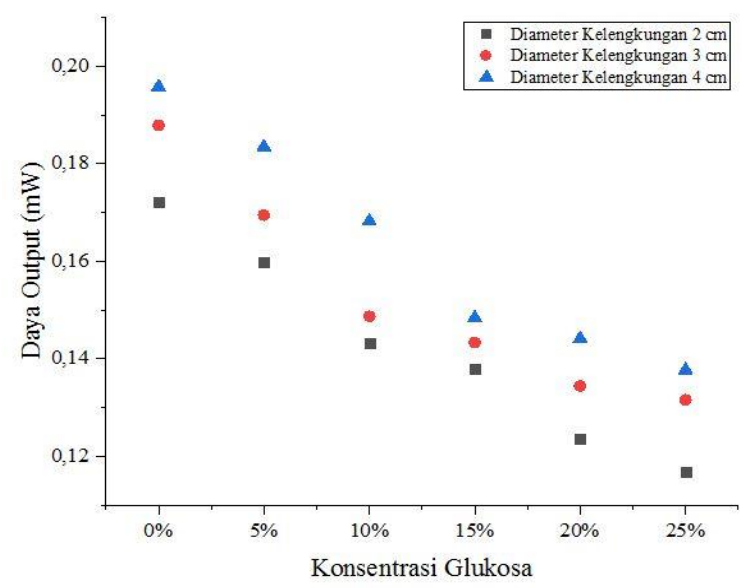

Gambar 5. Hubungan Daya Keluaran dengan Konsentrasi Glukosa pada Panjang Kupasan $2 \mathrm{~cm}$.

Pengambilan data kalibrasi ini dilakukan pengulangan sebanyak sepuluh kali, kemudian diambil nilai rata-ratanya. Tegangan yang digunakan $8 \mathrm{~V}-10 \mathrm{~V}$, sebab pada saat diberikan tegangan dibawah 8V BF5R-D1-N tidak menyala dan saat diberikan tegangan lebih dari $10 \mathrm{~V}$ nilai yang terbaca pada BF5R-D1-N dan Optical Power Meter memiliki nilai yang tetap.

Dari hasil pengukuran konsentrasiglukosa diperoleh grafik sebagai pada Gambar 5, Gambar 6, dan Gambar 7.

Dari hasil pengukuran daya keluaran dapat dilakukan perhitungan nilai sensitivitas dan resolusi. Sensitivitas yaitu perbandingan perubahan daya keluaran terhadap perubahan konsentrasi, dan resolusi yaitu nilai kosentrasi terkecil yang dapat diukur oleh sensor.

Sensitivitas pada penelitian ini dapat dihitung dengan persamaan sebagai berikut:

$$
\mathrm{S}=\frac{W_{\max }-W_{\min }}{\%_{\max }}
$$

dimana $\%_{\max }$ merupakan persen konsentrasi glukosa maksimum pada pengukuran ini.

Resolusi pada penelitian ini dapat dihitung dengan persamaan sebagai berikut:

$$
\mathrm{R}=\frac{N}{S}
$$

dimana $\mathrm{N}$ adalah skala terkecil dari optical power meter yaitu $0,001 \mu \mathrm{W}$ dan $\mathrm{S}$ adalah nilah sensitivitas.

\section{B. Pembahasan}

Penelitian analisis sensor pengukuran konsentrasi glukosa dengan prinsip macrobending pada serat optik multimode stepindex telah dilakukan dengan variasi diameter kelengkungan sebesar $2 \mathrm{~cm}, 3 \mathrm{~cm}$, dan $4 \mathrm{~cm}$ dan panjang kupasan $2 \mathrm{~cm}, 3$ $\mathrm{cm}$, dan $4 \mathrm{~cm}$. Larutan glukosa yang diuji memiliki konsentrasi 0\% (aquades), 5\%, 10\%, 15\% dan 25\%. Sumber cahaya digunakan dalam penelitian ini yaitu LED merah yang terdapat pada BF5R-D1-N dengan panjang gelombang 660 $\mathrm{nm}$. LED yaitu semikonduktor dengan sambungan $\mathrm{p}-\mathrm{n}$ yang memancarkan cahaya bila diberi tegangan bias maju. Detektor yang digunakan juga terdapat pada BF5R-D1-N yaitu fototransistor tipe NPN. 


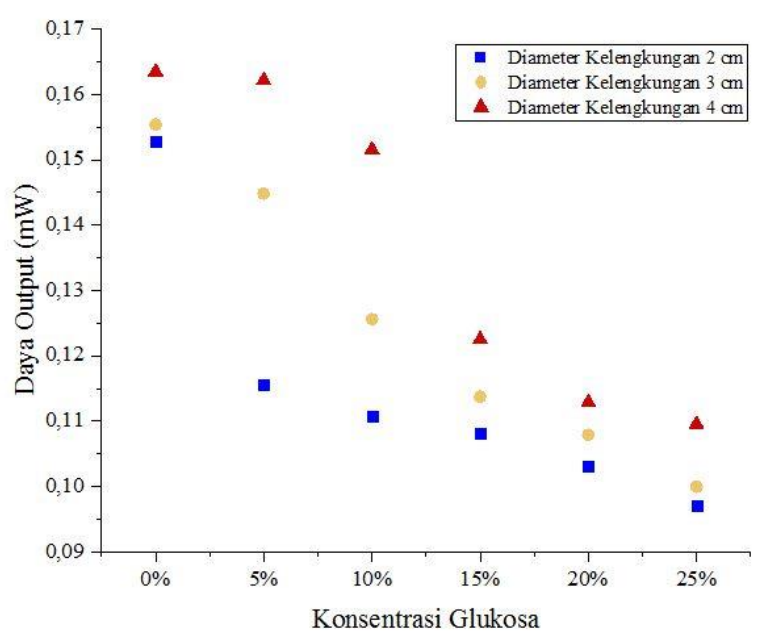

Gambar 6. Hubungan Daya Keluaran dengan Konsentrasi Glukosa pada Panjang Kupasan $3 \mathrm{~cm}$.

Fototransistor tipe NPN yaitu semikonduktor tipe P yang diapit oleh tipe $\mathrm{N}$, dimana semikonduktor tipe $\mathrm{P}$ menjadi basis, semikonduktor tipe $\mathrm{N}$ dengan elektron lebih banyak menjadi emitor, sedangkan semikonduktor tipe $\mathrm{N}$ dengan elektron lebih sedikit sebagai kolektor.

Dalam penelitian ini sebelum dilakukan proses pengambilan data dilakukan kalibrasi alat terlebih dahulu dengan membandingkan hasil keluaran pada BF5R-D1-N dengan optical power meter dengan cara menghubungkan input BF5R-D1-N dengan output BF5R-D1-N menggunakan serat optik sepanjang $10 \mathrm{~cm}$, diamati perubahan keluaranya seiring dengan bertambahnya tegangan yang diberikan dan didapatkan hasil pengukuran pada Tabel 1, dan dilakukan hal yang sama input BF5R-D1-N dihubungkan dengan detektor pada optical power meter dengan serat optik sepanjang $10 \mathrm{~cm}$ dan diamati perubahan daya keluaranya seiring bertambahnya tegangan yang diberikan dan didapatkan hasil pengukuran seperti pada Tabel 2. Dari kedua hasil pengukuran tersebut dapat disajikan dalam bentuk grafik yang terlihat pada Gambar 4, dan didapat regresi linier, sebagai persamaan kalibrasi.

Pada pembuatan daerah sensing, harus sangat berhati-hati agar tidak ada cacat didaerah permukaan core, karena hal ini berpotensi mempengaruhi daya keluaran. Pembuatan daerah sensing atau daerah kupasan yang tidak rata menyebabkan pemantulam dalam total terjadi, karena yang terjadi adalah pemantulan baur. Sehingga diperlukan pengamatan kerataan permukaan core dengan mikroskop stereo.

Konsentrasi larutan merupakan perbandingan antara zat terlarut terhadap pelarutnya dalam percobaan ini menggunakan glukosa sebagai zat terlarut dan aquades sebagai pelarutnya. Hubungan antara konsentrasi larutan dengan rugi daya dapat dijelaskan sebagai berikut, semakin besar konsentrasi, maka medium juga semakin rapat sehingga kecepatan cahaya dalam medium semakin rendah, indeks bias semakin besar. Indeks bias dapat didefinisikan sebagai perbandingan antara kecepatan cahaya dalam ruang hampa udara dengan cepat rambat cahaya pada suatu medium.

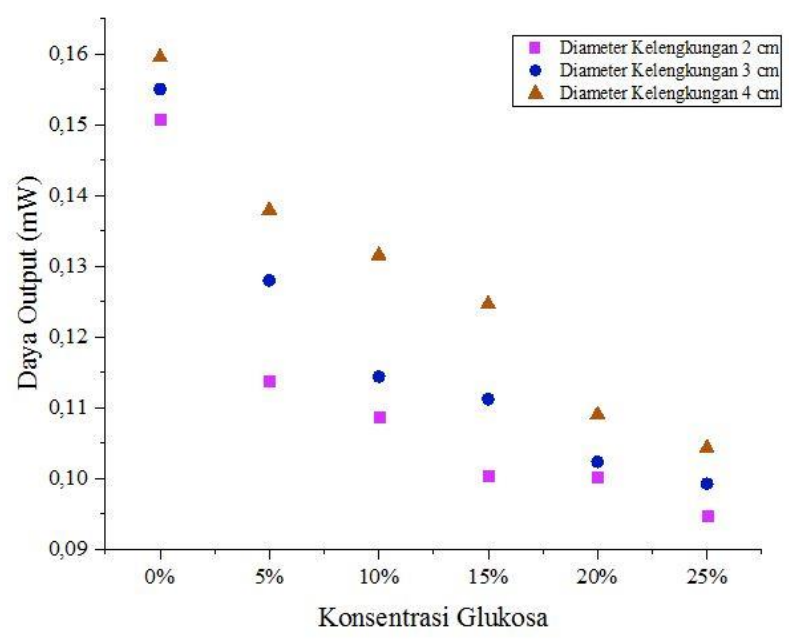

Gambar 7. Hubungan Daya Keluaran dengan Konsentrasi Glukosa pada Panjang Kupasan $4 \mathrm{~cm}$.

Perambatan cahaya dalam serat optik berdasarkan prinsip pemantulan dalam total. Cahaya dapat mengalami pemantulan dalam total jika memenuhi dua persyaratan yaitu indeks bias core lebih besar dari indeks bias cladding dan sudut datang cahaya lebih besar dari sudut kritis. Besar sudut kritis ini bergantung pada indeks bias core dan cladding. Pada penelitian ini, sepanjang daerah kupasan peran cladding digantikan oleh larutan glukosa dengan konsentrasi $0 \%, 5 \%$, $10 \%$, $15 \%$ dan $25 \%$. Besarnya konsentrasi mempengaruhi indeks bias sehingga hal ini berpengaruh pada sudut kritis. Indeks bias cladding yang semakin besar, membuat sudut kritis semakin besar pula. Hal ini menyebabkan sinar yang ditransmisikan pada daerah sepanjang kupasan menurun, karena banyak sinar dengan sudut datang yang lebih kecil menyebabkan sinar terbias keluar dari core.

Besar daya keluaran selain dipengaruhi oleh konsentrasi larutan, juga dipengaruhi oleh panjang kupasan. Semakin panjang daerah kupasan semakin banyak sinar yang dibiaskan keluar dari core, sehingga daya keluaran semakin kecil saat panjang kupasan semakin besar. Besar diameter kelengkungan juga mempengaruhi daya keluaran, semakin kecil diameter kelengkungan sinar yang terbias keluar dari core semakin banyak, hal ini dikarenakan perubahan bidang normal pada batas permukaan core dan larutan dari posisi sebelum dilengkungkan besar, menyebabkan sinar terbias keluar dari core semakin besar.

Besar pengaruh panjang kupasan, diameter kelengkungan, dan konsentrasi dapat dilihat pada grafik Gambar 5, 6, dan 7. Pada ketiga grafik tersebut dapat diketahui semakin besar konsentrasi larutan glukosa yang diuji semakin kecil daya keluaran yang terukur. Semakin panjang daerah kupasan semakin kecildaya keluaran, dan semakin besar diameter kelengkungan semakin besar pula daya keluaran yang terukur hal ini dikarenkan sesuai dengan pembahasan pada paragraf sebelumnya.

Adapun faktor lain yang dapat mempengaruhi daya keluaran yang terukur adalah evanescent wave. Pada faktor ini yang berpengaruh juga perbedaan indeks bias core dan indeks 
Tabel 3.

Hasil Perhitungan nilai sensitivitas dan resolusi sensor

\begin{tabular}{cccc}
\hline \hline $\begin{array}{c}\text { Panjang } \\
\text { Kupasan }\end{array}$ & $\begin{array}{c}\text { Diameter } \\
\text { Kelengkungan }\end{array}$ & $\begin{array}{c}\text { Nilai } \\
\text { Sensitivitas } \\
(\mathrm{mW} / \%)\end{array}$ & Resolusi \\
\hline \multirow{2}{*}{$2 \mathrm{~cm}$} & $2 \mathrm{~cm}$ & 0,221 & 0,000005 \\
& $3 \mathrm{~cm}$ & 0,214 & 0,000005 \\
& $4 \mathrm{~cm}$ & 0,214 & 0,000005 \\
$3 \mathrm{~cm}$ & $2 \mathrm{~cm}$ & 0,223 & 0,000004 \\
& $3 \mathrm{~cm}$ & 0,222 & 0,000005 \\
& $4 \mathrm{~cm}$ & 0,216 & 0,000005 \\
$4 \mathrm{~cm}$ & $2 \mathrm{~cm}$ & 0,224 & 0,000004 \\
& $3 \mathrm{~cm}$ & 0,223 & 0,000004 \\
& $4 \mathrm{~cm}$ & 0,221 & 0,000005 \\
\hline \hline
\end{tabular}

bias larutan pada daerah kupasan. Semakin besar indeks bias larutan semakin besar pula nilai $d p$ (kedalaman penetrasi) yang dialami, sinar yang melewati core serat optik dengan cladding larutan glukosa akan mengalami absorpsi sehingga terjadi pelemahan.

Pada penelitian ini, dihitung pula nilai sensitivitas dan resolusi. Sensitifitas yaitu perbandingan antara perubahan daya keluaran dengan perubahan konsentrasi. Nilai sensitivitas semakin besar jika ukuran diameter kelengkungan diperkecil, dan panjang kupasan diperbesar. Nilai sensitivitas telah disajikan pada Tabel 3, nilai sensitivitas terbesar yaitu 0,224 $\mathrm{mW} / \%$ pada serat optik dengan diameter kelengkungan $4 \mathrm{~cm}$ dan panjang kupasan $2 \mathrm{~cm}$. Nilai resolusi juga telah disajikan pada Tabel 3. Resolusi adalah nilai konsentrasi terkecil yang dapat diukur, nilai resolusi berbanding terbalik dengan sensitivitas, pada penelitian ini resolusi pengukuran sebesar $0,000005 \%$ dan $0,000004 \%$.

\section{KESIMPULAN}

Berdasarkan hasil pengukuran dan perhitungan dapat diambil kesimpulan diantaranya, pengaruh diameter kelengkungan terhadap daya keluaran berbanding lurus, semakin besar diameter kelengkungan semakin besar daya keluaran. Sedangkan pengaruh panjang kupasan terhadap daya keluaran berbanding terbalik, semakin besar panjang kupasan semakin kecil daya keluaran yang didapat, dan sensitivitas semakin besar seiring bertambahnya panjang kupasan, dan semakin kecilnya diameter kelengkungan yang diberikan, dimana nilai sensitivitas terbesar yaitu $0,224 \mathrm{~mW} / \%$ pada serat optik dengan diameter kelengkungan $4 \mathrm{~cm}$ dan panjang kupasan $2 \mathrm{~cm}$. Sedangkan resolusi berbanding terbalik dengan sensitivitas, dimana nilai resolusi sebesar $0,000005 \%$ dan $0,000004 \%$.

\section{DAFTAR PUSTAKA}

[1] Thomas, Optoelektronika Komunikasi Serat Optik. Yogyakarta: Andi Offset, 1995.

[2] S. Wayan, M. S. Muntini, and A. M. Hatta, "Pengembangan Sensor Napas Berbasis Serat Optik Plastik dengan Cladding Terkelupas untuk Aplikasi di Bidang Medis," J. Fis. dan Apl., vol. 8, no. 2, 2012.

[3] D. Li, Y. Sunb, S. Yuc, C. Sunb, H. Yub, and K. Xua, “U-shaped fiber-optic ATR sensor enhanced by silver nanoparticles for continuous glucose monitoring," Biosens. Bioelectron., vol. 72, p p. 370-375, 2013.

[4] D. Li, Y. Sunb, S. Yuc, C. Sunb, H. Yub, and K. Xua, "A-singleloop fiber attenuated total reflection sensor enhanced by silver nanoparticles for continuous glucose monitoring," Sensors and Actuators, vol. 220,pp. 1033-1042, 2015.

[5] K. Gerd, Optical Fiber Communications, 3rded. New York: Mc Graw Hill, 1993.

[6] E. Crisp, Sebuah Pengantar: Serat Optik. Jakarta: Erlangga, 2005.

[7] F. Pedrotti, Introduction to Optics. USA: Prentice Hal, Inc, 1993.

[8] W. M. Yunus, Refractive Index of Solution at High Concentrations. OSA, 1993. 